http://jmscr.igmpublication.org/home/ ISSN (e)-2347-176x ISSN (p) 2455-0450

crossref DOI: https://dx.doi.org/10.18535/jmscr/v8i11.32

Journal Of Medical Science And Clinical Research

\title{
Glycemic variability among type 2 diabetes patients with chronic kidney disease (CKD) using continuous glucose monitoring: a study from a tertiary care hospital
}

\author{
Authors \\ Dr Prabhakar $K^{1}$, Dr M Sasi Sekhar ${ }^{2}$, Dr Anitha $\mathrm{A}^{3}$ \\ ${ }^{1}$ MBBS, MD General Medicine, Professor \\ ${ }^{2}$ MBBS, MD General Medicine, Post Graduate \\ ${ }^{3}$ MBBS, MD General Medicine, Assistant Professor
}

\begin{abstract}
This study was designed to study the short term oscillations of glucose levels for a period of 3 days by using continuous glucose monitoring (CGM) as it uses glucose as a more important clinical tool, for a more definitive understanding of glycemic variability and its role in diabetic individuals with CKD and thus foreseeing the complications and its better management among high risk individuals.

Materials \& Methods: Diabetic individuals > 18 years with chronic kidney disease attending outpatient and inpatient of SRI DEVARAJ MEDICAL COLLEGE and RL JALAPPA Hospital. Study Duration: 3 months. Study design: Hospital based observational study. Inclusion criteria: Adults with Type 2 Diabetes Mellitus and Diagnosed with CKD (Either Kidney damage or GFR $<60 \mathrm{ml} / \mathrm{min} / 1.73 \mathrm{~m} 2$ for $\geq 3$ Months NKF KDIOQI guidelines).Exclusion criteria: Adults with Diagnosed primary kidney diseases, Congenital/ Acquired anatomical defects of the kidney, Obstructive nephropathies, Pregnancy and lactation. Sampling method: Purposive sampling, Sample size: - 50 subjects

Results: In our study $78 \%$ of the subjects were male and $22 \%$ of the subjects were female. In our study $94 \%$ of the subjects had hypertension, $46 \%$ of the subjects had CAD and $12 \%$ of the subjects had strokes. Multiple co-morbidities was present around $44 \%$ of the subjects.

Similar finding was present in our study majority of the subjects had stage 4 CKD.

In our study $46 \%$ were overweight, $22 \%$ of the subjects were in obesity class $1,14 \%$ of the subjects were in obesity class 2 and only $18 \%$ of the subjects had normal weight.

Discussion: In our study MODD estimation of inter-day glucose variability which was significantly higher in CKD stage 4, 5 when compared with CKD stage 1, 2, 3. Inter day glucose variability increases as the CKD stage increases similar to a study done Cristina et al.

Keywords: Glycaemic variability, Chronic kidney disease, Continuous glucose monitoring system.
\end{abstract}

\section{Introduction}

Diabetes mellitus is the most common cause of chronic kidney disease (CKD) in the world, leading to multiple complications including endstage renal disease, cardiovascular disease, infection and death ${ }^{(1)}$. It is the result of diabetes as well as associated co-morbidities such as hypertension and obesity. Approximately 20-30\% of patients with diabetes have renal impairment, classified as moderate to severe CKD (GFR $<60$ $\mathrm{ml} / \mathrm{min} / 1.73 \mathrm{~m} 2)^{(2)}$. 
CKD in setting of diabetes or diabetic kidney disease, manifests clinically as albuminuria, reduced glomerular filtration rate (GFR) or both. Glycemic variability in diabetics refers to variation around the mean blood glucose or fluctuations in blood glucose levels between high/peak and low/nadir levels.

Increased glycemic variability in diabetics with CKD can be attributed to a multitude of factors which include changes in insulin signaling, glucose transport, accumulation of uremic toxins, inflammatory mediators and oxidative stress, inducing insulin resistance, decreased renal gluconeogenesis, altered metabolism of medications and decreased insulin clearance.

Several studies indicated that glycemic variability seems to be an independent cardiovascular risk factor and has more deleterious effects on endothelial function compared to sustained hyperglycemia, especially due to oxidative stress activation ${ }^{(3,4) \text {. }}$

A study conducted by Modi et al, which provided the first population-based ESRD incidence data from India, demonstrated diabetes to be the leading cause of $\mathrm{CKD}^{(5)}$ and also a study done by Mohan MR et al which was the first report of Indian CKD registry conducted in 2012, which took into consideration 52,273 adult patients throughout India, concluded Diabetic nephropathy to be the most commonest cause (31\%), followed by CKD of undetermined etiology ${ }^{(6)}$.

A study in 2016 based on a report of discussions from an interdisciplinary group of experts in the areas of endocrinology, diabetology and nephrology detailed the relationship between diabetes and kidney disease which stresses on the need for appropriate glucose monitoring as glucose homeostasis is extremely altered in diabetics with CKD and both high and low glycemic levels are associated with increased morbidity and shortened survival in this group of patients $^{(7)}$.

Hence the need for study of glycemic variability in CKD patients is of utmost importance, whereas A1c and fructosamine, which are routine markers of glycemic control in diabetic populations, were shown to inappropriately reflect glycemic control, nearly 20 years ago, in diabetic patients with $\mathrm{CKD}^{(8,9)}$.

A recent review on role for glycemic variability in diabetic kidney disease conducted in University of Washington last year also shows that all available glycemic biomarkers, including A1c and glycated proteins, have limitations and should be used cautiously in setting of diabetic kidney disease as other methods such as continuous glucose monitoring (CGM) and self-monitoring of blood glucose (SMBG) are better measures of glycemic variability and overall diabetes control ${ }^{(10)}$. HbA1c(A1c) which is widely considered as the gold standard in assessing glucose control in diabetes, however is not a true reflection of average glucose in Diabetic Kidney Disease, because its accuracy is compromised by variables affecting RBC survival and other factors.

Several analyses, including glucose, A1c, fructosamine, glycated albumin and 1,5 anhydroglucitol are available for the evaluation of glycemia but it does not reflect short-term oscillations in blood glucose on a smaller scale of hours to days.

No two individuals with diabetes are the same with respect to glycemic control i.e., they can have same average A1c value with markedly different overall glycemic controls due to excursions in glucose levels.

Hence the current observational study is designed to study the short term oscillations of glucose levels for a period of 3 days by using continuous glucose monitoring (CGM) as it uses glucose as a more important clinical tool, for a more definitive understanding of glycemic variability and its role in diabetic individuals with CKD and thus foreseeing the complications and its better management among high risk individuals.

\section{Materials\& Methods}

Source of Data: Diabetic individuals $>18$ years with chronic kidney disease attending outpatient 
and inpatient of SRI DEVARAJ MEDICAL COLLEGE and RL JALAPPA Hospital.

Study Duration: 3 months.

Study Design: Hospital based observational study Inclusion Criteria: Adults with Type 2 Diabetes Mellitus and Diagnosed with CKD (Either Kidney damage or GFR $<60 \mathrm{ml} / \mathrm{min} / 1.73 \mathrm{~m} 2$ for $\geq 3$ Months -NKF KDIOQI guidelines)

\section{Exclusion Criteria: Adults with}

1. Diagnosed primary kidney diseases

2. Congenital/ Acquired anatomical defects of the kidney

3. Obstructive nephropathies

4. Pregnancy and lactation

Sampling Method: Purposive sampling

\section{Sample Size Calculation:}

Considering the $96.0 \%$ prevalence as per literature in India, with $95 \%$ confidence interval and absolute error (L) of 36 , the total sample size of 40.96 was calculated. The formula used was $n=z^{2}$ $\left(\mathrm{pq} / \mathrm{L}^{2}\right)$, where, $\mathrm{z}=1.96$ at $95 \%$ confidence interval, $\mathrm{p}=$ estimated prevalence (96.0\%), $\mathrm{q}=100-\mathrm{p}$ (4.0\%) and $\mathrm{L}=$ permissible error (absolute error of $6 \%$, the total sample size of 50 was considered for the study. The sample size of 41 was obtained. Considering the non-response rate of $10.0 \%, 41+4 \approx 45$ was the minimum sample size. For the convenience of analysis, minimum of 50 were selected.

\section{Materials}

1. Continuous glucose monitor -5 days Routine preliminary investigations such as:

2. RFT

3. Fasting blood glucose, Post prandial blood glucose ( $2 \mathrm{hr}$ )

4. $\mathrm{HbA} 1 \mathrm{c}$

5. Fasting lipid profile

6. USG abdomen and pelvis to rule out congenital / acquired anatomical defects

7. $\mathrm{CBC}$

8. Urine routine and microscopy

\section{Method of Collection of Data}

After ethical committee approval and obtaining written informed consent from the patients, the study will be undertaken.

\section{Study Protocol}

Subjects fulfilling inclusion criteria will be selected for the study. Each subject will make one visit to the study hospital during which medical history including socioeconomic status, physical examination, systemic examinations and relevant investigations will be carried out. General examination including vitals i.e. pulse, blood pressure, BMI will be recorded. Systemic examination of cardiovascular, abdomen, nervous system, respiratory system will be done. The short term fluctuations of glucose levels will be monitored using Continuous glucose monitor (CGM) - Medtronic system.

The glycaemic variability indices were assessed on CGM readings using the Gly Culator Application $^{[11,12]}$

Mean level of $24 \mathrm{~h}$ interstitial glucose value (MIG), Mean amplitude of glycemic excursion (MAGE) calculated based on mean ofdifferences between consecutive glucose values picks and nadirs, only for differences greater than SD. MAGE provides a measure of intra-day, high amplitude, glucose variability ${ }^{[13] . ~ M e a n ~ o f ~ d a i l y ~}$ differences (MODD) calculated as the mean of absolute differences between glucose values at corresponding time points of consecutive days. MODD allows the estimation of inter-day glucose variability ${ }^{[14]}$.

\section{Statistically Analysis}

Data was entered into Microsoft excel data sheet and was analyzed using SPSS 22 version software. Categorical data was represented in the form of Frequencies and proportions. Continuous data was represented as mean and standard deviation. Comparisons

Between different groups were performed using parametric or nonparametric tests, depending of the variables distribution. 


\section{Results}

In our study we have included 50 study subjects. $78 \%$ of the subjects were male and $22 \%$ of the subjects were female. Minimum age of the subjects in our study was 49yrs and maximum $88 \mathrm{yrs}$. Mean age was $68.45 \pm 11.36 \mathrm{yrs}$.

$94 \%$ of the subjects had hypertension, $46 \%$ of the subjects had CAD and $12 \%$ of the subjects had strokes. Multiple co-morbidities was present around $44 \%$ of the subjects.

According to the stages of CKD majority of the subjects i.e. $40 \%$ of the subjects had stage 4 followed by $28 \%$ of the subjects had stage 3, $18 \%$ of the subjects had stage $5,8 \%$ of the subjects had stage 2 and only $6 \%$ of the subjects had stage 1 .

Majority of subjects $46 \%$ were overweight, $22 \%$ of the subjects were in obesity class $1,14 \%$ of the subjects were in obesity class 2 and only $18 \%$ of the subjects had normal weight.

Table 1:- Characteristic features of study subjects.

\begin{tabular}{|l|c|}
\hline & \\
\hline Age in years & $68.45 \pm 11.36$ yrs \\
\hline SEX & \\
\hline Male & $39(78 \%)$ \\
\hline Female & $11(22 \%)$ \\
\hline MEDICAL HISTORY & \\
\hline Hypertension & $47(94 \%)$ \\
\hline CAD & $23(46 \%)$ \\
\hline Stroke & $6(12 \%)$ \\
\hline Stages of CKD & \\
\hline stage 1 & $3(6 \%)$ \\
\hline stage 2 & $4(8 \%)$ \\
\hline stage 3 & $14(28 \%)$ \\
\hline stage 4 & $20(40 \%)$ \\
\hline stage 5 & $9(18 \%)$ \\
\hline BMI & \\
\hline$\leq 25 \mathrm{~kg} / \mathrm{m} 2$ & $9(18 \%)$ \\
\hline$>25-\leq 30 \mathrm{~kg} / \mathrm{m} 2$ & $23(46 \%)$ \\
\hline$>30-\leq 35 \mathrm{~kg} / \mathrm{m} 2$ & $11(22 \%)$ \\
\hline$>35 \mathrm{~kg} / \mathrm{m} 2$ & $7(14 \%)$ \\
\hline
\end{tabular}

Mean HbA1c in subjects who CKD stage 1,2,3 was $7.2 \pm 1.4$ and Mean HbA1c in subjects who CKD stage 4,5 was $8.4 \pm 0.8$. There was statistically significant difference found between CKD stages with respect to $\mathrm{HbA1c}$.
Mean MIG in subjects who CKD stage 1,2,3 was 161.2 \pm 29.8 and Mean MIG in subjects who CKD stage 4,5 was $211.2 \pm 45.4$. There was statistically significant difference found between CKD stages with respect to MIG

Mean MAGE in subjects who CKD stage 1,2,3 was 108.7 \pm 36.4 and Mean MAGE in subjects who CKD stage 4,5 was $168.4 \pm 53.6$. There was statistically significant difference found between CKD stages with respect to MAGE.

Mean MODD in subjects who CKD stage 1,2,3 was 42.6+12.1 and Mean MODD in subjects who CKD stage 4,5 was 51.6 \pm 17.4. There was statistically significant difference found between CKD stages with respect to MODD.

Table 2: Comparison of glycaemic variability indices according to CKD stage

\begin{tabular}{|l|c|c|c|}
\hline & $\begin{array}{c}\text { CKD stage } \\
1,2,3\end{array}$ & $\begin{array}{c}\text { CKD stage } \\
4 \& 5\end{array}$ & $\begin{array}{c}\text { P } \\
\text { value }\end{array}$ \\
\hline HbA1c & $7.2 \pm 1.4$ & $8.4 \pm 0.8$ & $<0.01$ \\
\hline $\begin{array}{l}\text { Mean level of 24 h } \\
\text { interstitial glucose } \\
\text { Value (MIG) }\end{array}$ & $161.2 \pm 29.8$ & $211.2 \pm 45.4$ & $<0.01$ \\
\hline $\begin{array}{l}\text { Mean amplitude of } \\
\text { glycaemic excursion } \\
\text { MAGE) }\end{array}$ & $108.7 \pm 36.4$ & $168.4 \pm 53.6$ & $<0.01$ \\
\hline $\begin{array}{l}\text { Mean of daily } \\
\text { differences (MODD) }\end{array}$ & $42.6 \pm 12.1$ & $51.6 \pm 17.4$ & 0.0358 \\
\hline
\end{tabular}

\section{Discussion}

In our study $78 \%$ of the subjects were male and $22 \%$ of the subjects were female. Similar finding was found in study done by Presswala et $\mathrm{al}^{15}$.

In our study $94 \%$ of the subjects had hypertension, $46 \%$ of the subjects had CAD and $12 \%$ of the subjects had strokes. Multiple co-morbidities was present around $44 \%$ of the subjects.

Our finding was Similar to the study done by Presswala et al ${ }^{15}$

In study done by Presswala et al ${ }^{15} 18.75 \%$ of subjects had GFR less than $15 \mathrm{ml} / \mathrm{min}, 42.5 \%$ of the subjects had GFR between $15-30 \mathrm{ml} / \mathrm{min}$ and $38.75 \%$ had GFR $30-45 \mathrm{ml} / \mathrm{min}$.

Similar finding was present in our study majority of the subjects had stage 4 CKD.

In our study $46 \%$ were overweight, $22 \%$ of the subjects were in obesity class $1,14 \%$ of the subjects were in obesity class 2 and only $18 \%$ of the subjects had normal weight. 
In a study done by Presswala et $\mathrm{al}^{15}$ overweight was present in $41.25 \%$, Obesity class 1 in 26.25 and obesity class 2 in $15 \%$.

In our study MODD estimation of inter-day glucose variability which was significantly higher in CKD stage 4, 5 when compared with CKD stage $1,2,3$. Inter day glucose variability increases as the CKD stage increases.

In a study done Cristina et $\mathrm{al}^{16}$ diabetic patients with CKD had statistic significantly higher interday (MODD) variability comparative to diabetic and non-diabetic subjects with normal kidney function.

In our study intra-day variability was estimated by MAGE and MIG which was significantly higher in CKD stage 4, 5 when compared with CKD stage $1,2,3$. Intraday glucose variability increases as the CKD stage increases.

In a study done Cristina et al ${ }^{16}$ diabetic patients with CKD hadstatistic significantly higher intraday (MAGE, MIG) variability comparative to diabetic and non-diabetic subjects with normal kidney function.

In our study there was statistically significant difference found between CKD stages with respect to $\mathrm{HbA1c}$.

In a study done Cristina et $\mathrm{al}^{16} \mathrm{HbA} 1 \mathrm{c}$ was higher in CKD diabetic patients than in diabetic patients without CKD but the differences did not reach statistical significance.

Various studies lack of correlation between meaninterstitial glucose assessed on CGMS recordings and $\mathrm{HbAlc}$, indicating that CGMS could be more accurate in the evaluation of realtime glycaemic control in this patients category ${ }^{[17-19]}$.

\section{Conclusions}

We can conclude that Subjects with Late stages of CKD (stage 4\&5) and diabetes had metabolic imbalance and significant glycaemic variability compared to subjects with early stage of CKD (stage 1,2,3) and Diabetes. Glycaemic variability directly proportional to stages of CKD.

\section{Acknowledgements}

Authors would like to acknowledge all the subjects participated in the study. Everyone who contributed in the completion of the study including the technical staff

\section{Declarations}

Funding: No Funding Sources

Conflict of Interest: None Declared

\section{Reference}

1. Tuttle KR, Baris GL, Bilous RW, etal. Diabetic kidney disease: a report from an ADA consensus conference. Diabetes care. 2014;37(10):2864-2883

2. Huang ES, Liu JY, Moffet HH, John PM, Karter AJ. Glycemic control complications, and death in older diabetic patients: the diabetes and aging study. Diabetes care. 2011; 34(6): 1329-1336.

3. Siegelaar SE, Holleman F, Hoekstra JB, De Vries $\mathrm{JH}$, et al. Glucose variability; does it matter?. Endocr Rev (2010); 31:171-182.

4. Monnier L, Colette C, et al. Glycemic variability: should we and can we prevent it? Diabetes care 2008; 31:S150-S154

5. Modi GK, Jha V, et al. The incidence of end-stage renal disease in India: a population-based study. Kidney Int. 2006 Dec;70(12): 2131-2133

6. Mohan M Rajapurkar, George T John, et al. What do we know about chronic kidney disease in India: first report of indian CKD registry. BMC nephrology 2012, 13:10.

7. Pecoits-Filho R, Hugo Abensur, et al. Interactionsbetween kidney disease and diabetes: Dangerous liaisons. Diabetolmetabsyndr (2016); 8:50

8. McCance DR, Clarke KC, Kennedy L. Serum fructosamine in uraemia, myeloma and acute inflammatory disordersrelationship to serum glucose and aklbumin levels. Ann ClinBiochem 1989; 26(pt 1): 63-68 
9. Morgan L, Monsod T, Deucia M, et al. Glycated proteins as indices of glycemic control in diabetic patients with chronic renal failure. Diabet Med 1996; 13: 514519.

10. Savitha Subramanian, Irl B. Hirsch. Diabetic kidney disease: Is there a role of glycemic variability?. Current Diabetes Reports(2018);18:13

11. www.pediatria.umed.pl/team/glyculator. Accessed in June 2013

12. Czerwoniuk D, Fendler W, Walenciak L, Mlynarski W. GlyCulator: a glycemic variability calculation tool for continuous glucose monitoring data. JDiabetesSciTechnol 5: 447-451, 2011.

13. Wójcicki JM. Mathematical descriptions of theglucose control in diabetes therapy. Analysis of theSchlichtkrull "M"-value. HormMetab Res 27: 1-5, 1995.

14. Molnar GD, Taylor WF, Ho MM. Day-today variation of continuously monitored glycaemia: a further measure of diabetic instability. Diabetologia8: 342-348,1972.

15. Presswala L, Hong S, Harris Y, Romao I, Zhang M, Jhaveri KD, Sakhiya V, Fishbane S. Continuous Glucose Monitoring and Glycemic Control in Patients With Type 2 Diabetes Mellitus and CKD. Kidney Medicine. 2019 Sep 1;1(5):281-7.

16. Văduva C, Popa S, Moța M, Moţa E. Analysis of Chronic Kidney DiseaseAsociated Glycemic Variability in Patients with Type 2 Diabetes Using Continuous Glucose Monitoring System. Romanian Journal of Diabetes Nutrition and Metabolic Diseases. 2013 Sep $1 ; 20(3): 315-22$.
17. Vos FE, Schollum JB, Coulter CV, Manning PJ, Duffull SB, Walker RJ. Assessment of markers of glycaemic control in diabetic patients with chronic kidney disease using continuous glucose monitoring. Nephrology (Carlton) 17: 182 -188, 2012.

18. Kazempour-Ardebili S, Lecamwasam VL, Dassanyake $\mathrm{T}$ et al. Assessing glycemic control in maintenance hemodialysis patients with type 2 diabetes. Diabetes Care 32: 1137-1142, 2009.

19. Riveline JP, Teynie J, Belmouaz S et al. Glycaemic control in type 2 diabetic patients on chronic haemodialysis: use of a continuous glucose monitoring system. Nephrol Dial Transplant 24: 2866-2871, 2009. 